\title{
Epidemiology of Poisoning and Perception towards Poison Management Guidelines in Pediatricians of a Rural Children's Hospital in India
}

\author{
Dipak. D. Bharambe ${ }^{1}$, Dr. Mohanraj Rathinavelu ${ }^{2}$, Dr. Dixon Thomas ${ }^{3}$, \\ Dr. Y. Padmanabha Reddy ${ }^{4}$ \\ ${ }^{\text {I}}$ Pharm.D Intern, Department of Pharmacy Practice, Raghavendra Institute of Pharmaceutical Education and \\ Research, India). \\ ${ }^{2}$ (Assistant Professor, Department of Pharmacy Practice, Raghavendra Institute of Pharmaceutical Education \\ and Research, India). \\ ${ }^{3}$ (Professor, Head of Department, Department of Pharmacy Practice, Raghavendra Institute of Pharmaceutical \\ Education and Research, India). \\ ${ }^{4}$ Professor and Principal, Department of Analysis, Raghavendra Institute of Pharmaceutical Education and \\ Research, India).
}

\begin{abstract}
The current epidemiological survey study of six months was designed to evaluate the poisoning histories; and to develop standard treatment guidelines for the treatment of poisoning and also to evaluate the epidemiology of poisoning and perception of pediatrician towards poison management guidelines. In our study poison cases observed commonly were scorpion sting (42.31\%), kerosene (8.46\%), unknown bite (7.69\%), snake bite (6.15\%), organophosphorus compounds (4.16\%), pyrethronoid, head louse, vasmol, food poisoning $(3.85 \%)$, turpentine oil (2.30\%), transfluthrin (1.54\%). Childhood poisoning is a significant cause of morbidity and mortality in pediatric patients.

In conclusion, the rural district hospital which caters the healthcare needs of majority of the population in a wide geographical area, the number of reported cases of poisoning was fairly low for a period of 18 months. Higher awareness is required to prevent poisoning and to seek medical care. Poisoning incidences were high in the age group of 1-11 years compared to adults. Perception of pediatrician towards the poison management guidelines was very welcoming. It was found to be applicable, relevant, satisfactory, and complimentary to their real practice.
\end{abstract}

Keywords: Epidemiology, Morbidity, Mortality, Pediatrics, Toxicology

\section{INTRODUCTION}

Paracelsus over 400 years ago stated, "All substances are poisons, there is no such thing as a non - poison". The right dose differentiates a poison and a remedy. The safety of a chemical is defined as therapeutic index or ratio, which is LD50/ED50 [1]. Poisoning is a major problem in children all over the world. However, the offending agent and the associated morbidity and mortality vary from place to place and change over a period of time. Mortality due to poisoning in children below 4 years of age [2].

"Toxicology can be defined as that branch of science that deals with poisons, or the branch of medicine that deals with the detection and treatment of poisons is known as toxicology." Broader definitions of toxicology, such as "the study of the detection, occurrence, properties, effects, and regulation of toxic substances," although more descriptive, do not resolve the difficulties [3].

Over 5 million people are treated in USA every year on exposure to drugs. Only about $5 \%$ require hospitalization. Overall mortality rate is low, only $0.03 \%$ of all exposures, but $1-3 \%$ in suicidal cases. Acute poisoning accounts for $2-3 \%$ of all admissions to hospital in India. High incidence in the community reflects cases of availability of insecticides and pesticides and also stress of modern lifestyle. Insecticides, vegetable poisons, aluminium phosphide, alcohol, hypnotics and sedatives are the major poisons encountered in India. In rural areas, insecticides, pesticides and vegetable poison, predominate whereas in cities and towns it is sedatives or other drug over dosage. The figures are much higher in India and are increasing day by day [4], [5]. In the context of biology, poisons are substances that cause disturbances to organisms [6], usually by chemical reaction or other activity on the molecular scale, when a sufficient quantity is absorbed by an organism. The fields of medicine (particularly veterinary) and zoology often distinguish a poison from a toxin, and from venom. Toxins are poisons produced by some biological function in nature, and venoms are usually defined as 
toxins that are injected by a bite or sting to cause their effect, while other poisons are generally defined as substances absorbed through epithelial linings such as the skin or gut. Poisons are most often applied in industry, agriculture and other uses for other reasons than their toxicity. Pesticides are one application where they are indeed used for their toxicity [6]. A toxidrome (a portmanteau of toxic and syndrome) is a syndrome caused by a dangerous level of toxins in the body. The term was coined in 1970 by Mofenson and Greensher [7]. It is often the consequence of a drug overdose. A toxidrome may indicate a medical emergency requiring treatment at a poison control center. Aside from poisoning, a systemic infection may also lead to a toxidrome. "Classic" toxidromes are often variable [8] or obscured by the co-ingestion of multiple drugs [9].

Poisons can be classified based on its action as local effect, systemic effect, and combined effect. Poisons can also be classified as acute, chronic, sub acute and fulminant poisons. There are several ways of classifying poisons, for clinical and forensic purposes they can be classified as corrosives, irritants, neurotoxic, cardiovascular, asphyxiants poisons and substance of dependence [10]. Poisoning also refers to the development of dose related adverse effects following exposure to chemicals/ drugs / xenobiotics [1]. Assessment of perception among the healthcare professionals is very important due to increasing cases of admissions in hospitals due to poisoning. For which, regular updation of the protocol of poison management is made mandate.

\subsection{Study Design}

\section{Methodology}

Our study involves an epidemiological survey of poisoning reported in a rural hospital setting and perceptions of pediatricians about poison management guidelines. The study was descriptive in natures which focus on applicability of a newly prepared poison management guideline as hospital protocols in management of poisons in pediatric emergency wards.

\subsection{Study sample: 130 Patients}

\subsection{Study setting}

Department of Pediatrics and Emergency ward in Rural Development Trust (RDT) children hospital in Bathalapalli, Anantapur.

\subsection{Study period}

The project work was of a period of 6 months starting from January 2014 to June 2014.

2.4.1 Phase I: Literature review and finalizing the study methodology - One month

2.4.2 Phase II: Data collection, preparing handbook of poison management, and for surveying pediatricians as per study - Four months

2.4.3 Phase III: Processing and writing of project report. - One month

As part of the study retrospectively, 18 Months (July 2012 - December 2013) data were collected from hospital records about the epidemiology of poisoning reported in the hospital. One month after circulation of handbook of poison management, a survey was done to study the perception of pediatricians on the guidelines provided.

\subsection{Materials used}

Handbook of poison management, which was prepared mostly by referring ToxED software from Elsevier. ToxED is a new standard for clinical toxicology poisoning and overdose references; Gold Standard Inc. has launched ToxED. In drug overdose and poisoning emergencies, you can trust ToxED to help you make sound and confident clinical decisions. As your total clinical toxicology resource, ToxED delivers evidence-based information, helping you through the assessment, diagnosis and management of crucial drug and poisoning emergencies and need for quick access to concise and comprehensive information at the point-of-care for the diagnosis and treatment of poisonings, drug overdoses, and exposure to chemicals and hazardous waste.

The key topics in the book divided into part-I \& part-II, Part-I include assessment \& treatment of poisoning condition, sign, symptoms, Part-II contains method of use of antidote.

It was released on 24th March 2013 in National conference on Pharmacovigilance by Dr. Y.K. Gupta, Professor and Head, Department of Pharmacology, All India Institute of Medical Sciences, New Delhi and President of society of Toxicology, India and was president of the Indian Pharmacological society (2005-2006).

Self designed survey form to collect perception of pediatrician's applicability, acceptability and satisfaction towards quality of poison management guidelines. A copy of the form was attached in the appendix.

2.5.1 Data collection

The hospital records of all the pediatric patients. All cases of pediatric poisoning and noted their outcome. All children and adolescents aged less than 18 years with a definite history of poisoning were included. Children who had Pesticide poisoning, food poisoning, toxic or idiosyncratic reaction to prescribed drugs, snake bites and scorpion stings were included from the study. Data regarding age, sex, type of residence, type and quantity of 
substance consumed, time of ingestion, nature of ingestion, time of symptom onset, time of presentation to hospital, symptoms and signs, investigations, diagnostic and therapeutic interventions, and outcome was noted on a predesigned profoma. Interview of pediatricians were done to survey their perception about the newly prepared handbook of poison management.

2.5.2 Data processing

All the data from the duly filled and processed using Microsoft Excel spreadsheet. Results were documented and reported. Literature review was done and it was compared with our results in discussions.

The report was written using guidelines provided by Department of Pharmacy Practice in study site.

\section{Results and Discussions}

The present study involved 130 patients admitted in the study site due to poisoning, Demographic details of the participants involved in the study was categorized based on gender distribution, age wise distribution, the results of which were thoroughly analyzed and reported in Table. 1.

Table. 1. Demographic detail of the patients

\begin{tabular}{|c|c|c|c|}
\hline S. No & Demographic details & \multicolumn{2}{|c|}{$\begin{array}{c}\text { No. of Patients } \\
(\mathrm{n}=130)\end{array}$} \\
\hline \multirow{3}{*}{01} & \multirow{3}{*}{02} & Male & $\begin{array}{c}\text { Female } \\
55(42.3 \%)\end{array}$ \\
\hline \multirow{2}{*}{02} & Gender Distribution & $75(57.7 \%)$ & $07(5.38 \%)$ \\
\cline { 3 - 4 } & Age wise Distribution & 1 month -1 year & $99(76.15 \%)$ \\
\cline { 3 - 4 } & & 1 year -12 years & $24(18.46 \%)$ \\
\cline { 3 - 4 }
\end{tabular}

The details of cases collected during 18 months of retrospective study was reported in Figure 1

Fig. 1. Retrospective data of poison cases

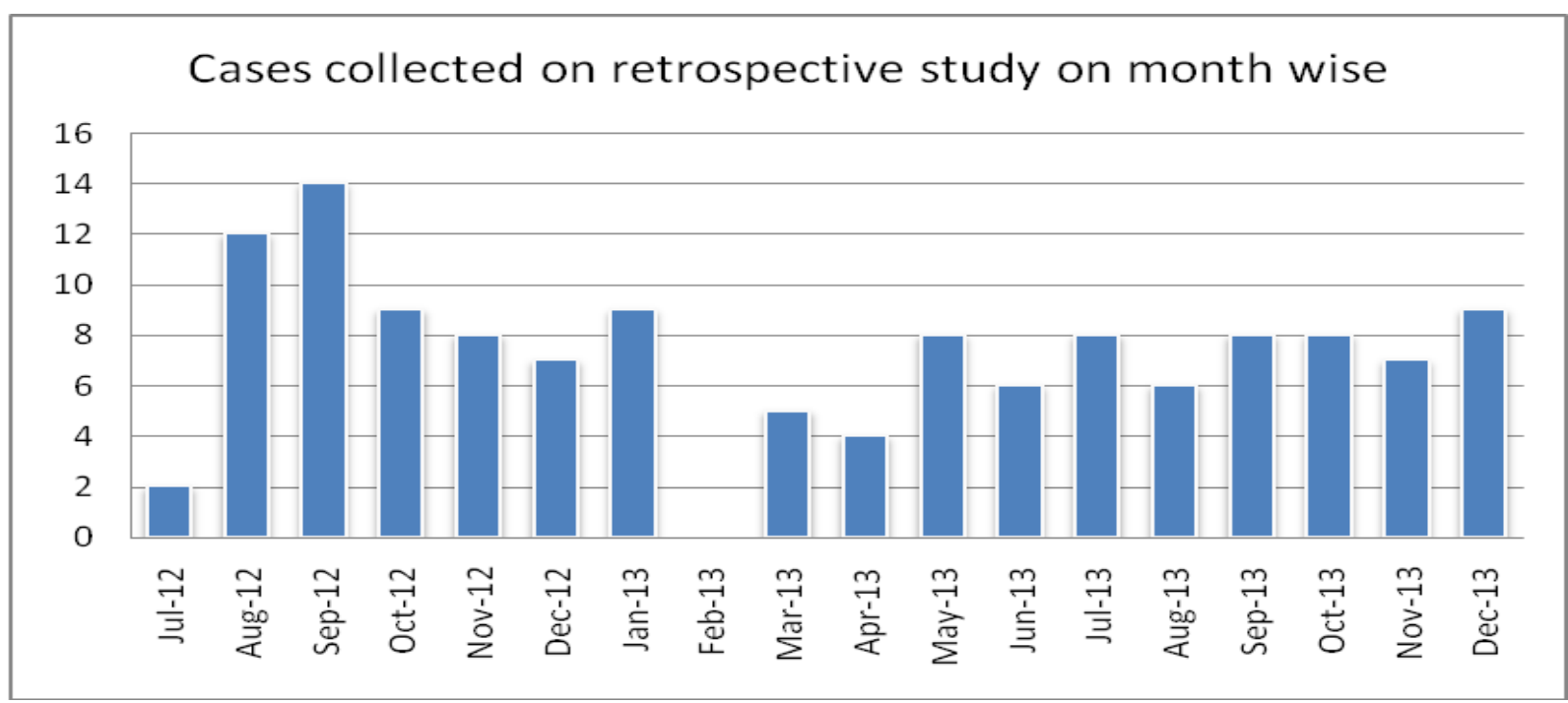

Most common agents responsible for poisoning were scorpion sting $(42.31 \%)$ followed by the poisoning due to kerosene $(8.46 \%)$, unknown bite $(7.69 \%)$, snake bite $(6.15 \%)$, organophosphorus compounds $(4.16 \%)$, pyrethronoid, head louse, vasmol, food poisoning $(3.85 \%)$, turpentine oil $(2.30 \%)$, All out (transfluthrin) $(1.54 \%)$.

Out of 130 total cases reported with poisoning 76 (58.46\%) were due to animal or insect bite. Out of animal or insect bite $55(72.37 \%)$ were due to scorpion sting. Next major identified was due to snake bite results are reported in Table. 2.

Out of 130 total cases reported with poisoning 20 (15.38\%) were due to Pesticides. Out of pesticide 06(30\%) were due to Organophosphates. Next major identified was pyrethronoid and head louse reported in Table. 3.

Out of 130 total cases reported with poisoning 29(22.31\%) were due to household drug/chemical. Out of household drug/chemical $11(37.93 \%)$ were due to kerosene. Next major identified was vasmol, turpentine, all out (transfluthrin) reported in Table. 4.

Out of 130 total cases reported with poisoning 5(3.85\%) were due to food, results reported in Table. 5. 
Table. 2. Poisoning due to Animal bites

\begin{tabular}{|c|c|c|c|c|c|c|c|c|c|}
\hline \multirow[t]{2}{*}{ S. No. } & \multirow[t]{2}{*}{$\begin{array}{l}\text { Nature of } \\
\text { poisoning }\end{array}$} & \multicolumn{3}{|c|}{$\begin{array}{l}\text { Age group } \\
\text { (yrs) }\end{array}$} & \multicolumn{2}{|c|}{ Sex } & \multicolumn{2}{|c|}{$\begin{array}{l}\text { Duration of stay } \\
\text { (Avg in days) }\end{array}$} & \multirow[t]{2}{*}{$\begin{array}{l}\text { Total } \\
\text { Cases }\end{array}$} \\
\hline & & Infants & Children & Adolescents & Male & Female & Males & Females & \\
\hline 01 & $\begin{array}{l}\text { Scorpion } \\
\text { Sting }\end{array}$ & 5 & 48 & 2 & 33 & 22 & 2.39 & 2.13 & 55 \\
\hline 02 & Snake Bite & 1 & 7 & - & 3 & 5 & 1 & 1.6 & 8 \\
\hline 03 & Monkey Bite & 1 & - & - & 1 & - & 10 & - & 1 \\
\hline 04 & Insect Bite & - & 1 & - & 1 & - & 2 & - & 1 \\
\hline 05 & $\begin{array}{c}\text { Honey Bee } \\
\text { Sting }\end{array}$ & - & - & 1 & 1 & - & 2 & - & 1 \\
\hline 06 & Unknown Bite & - & 5 & 5 & 8 & 2 & 1.0625 & 15.5 & 10 \\
\hline & Total & 7 & 61 & 8 & 47 & 29 & 18.452 & 19.23 & 76 \\
\hline
\end{tabular}

Table. 3. Poisoning due to Pesticides

\begin{tabular}{|c|c|c|c|c|c|c|c|c|c|}
\hline \multirow[t]{2}{*}{ S. No. } & \multirow[t]{2}{*}{$\begin{array}{l}\text { Nature of } \\
\text { poisoning }\end{array}$} & \multicolumn{3}{|c|}{$\begin{array}{c}\text { Age group } \\
\text { (yrs) }\end{array}$} & \multicolumn{2}{|c|}{ Sex } & \multicolumn{2}{|c|}{$\begin{array}{l}\text { Duration of stay } \\
\text { (Avg in days) }\end{array}$} & \multirow[t]{2}{*}{$\begin{array}{l}\text { Total } \\
\text { Cases }\end{array}$} \\
\hline & & Infants & Children & Adolescents & Male & Female & Male & Female & \\
\hline 01 & $\begin{array}{c}\text { Organo } \\
\text { Phosphate } \\
\text { Poisoning }\end{array}$ & - & 4 & 2 & 6 & - & 2.5 & - & 6 \\
\hline 02 & $\begin{array}{c}\text { Pyrethronoid } \\
\text { Poisoning }\end{array}$ & - & 4 & 1 & 4 & 1 & 1.5 & 2 & 5 \\
\hline 03 & $\begin{array}{l}\text { Herbicide } \\
\text { Poisoning }\end{array}$ & - & - & 1 & 1 & - & - & 3 & 1 \\
\hline 04 & $\begin{array}{l}\text { Pediculocide } \\
\text { Poisoning }\end{array}$ & - & 1 & - & - & 1 & - & 2 & 1 \\
\hline 05 & $\begin{array}{c}\text { Head Louse } \\
\text { Poison }\end{array}$ & - & 3 & 2 & 4 & 1 & 0.875 & 3 & 5 \\
\hline 06 & $\begin{array}{c}\text { Insecticide } \\
\text { Poisoning }\end{array}$ & - & 1 & - & 1 & - & 1 & - & 1 \\
\hline 07 & $\begin{array}{c}\text { Accidental } \\
\text { Bed Bug } \\
\text { Poisoning }\end{array}$ & - & 1 & - & 1 & - & 1 & - & 1 \\
\hline & Total & - & 14 & 6 & 17 & 3 & 6.09 & 10 & 20 \\
\hline
\end{tabular}


Table. 4. Poisoning due to Household chemicals / drugs

\begin{tabular}{|c|c|c|c|c|c|c|c|c|c|}
\hline \multirow[t]{2}{*}{ S. No } & \multirow[t]{2}{*}{$\begin{array}{l}\text { Nature of } \\
\text { Poisoning }\end{array}$} & \multicolumn{3}{|c|}{$\begin{array}{l}\text { Age Group } \\
\text { (Yrs) }\end{array}$} & \multicolumn{2}{|c|}{ Sex } & \multicolumn{2}{|c|}{$\begin{array}{c}\text { Duration Of Stay } \\
\text { (Avg. in Days) }\end{array}$} & \multirow[t]{2}{*}{$\begin{array}{l}\text { Total } \\
\text { Cases }\end{array}$} \\
\hline & & Infants & Children & Adolescents & Male & Female & Male & Female & \\
\hline 01 & $\begin{array}{c}\text { Vasmol } \\
\text { Poisoning }\end{array}$ & - & - & 5 & - & 5 & - & 2.6 & 5 \\
\hline 02 & $\begin{array}{l}\text { Kerosene } \\
\text { Poisoning }\end{array}$ & - & 11 & - & 5 & 6 & 3.8 & 3 & 11 \\
\hline 03 & $\begin{array}{c}\text { Turpentine Oil } \\
\text { Poisoning }\end{array}$ & - & 3 & - & 1 & 2 & 7 & 1.5 & 3 \\
\hline 04 & $\begin{array}{c}\text { Godrej Hair } \\
\text { Dye Poisoning }\end{array}$ & - & 1 & - & 1 & - & 1 & - & 1 \\
\hline 05 & $\begin{array}{c}\text { Shelcol } \\
\text { Poisoning }\end{array}$ & - & 1 & - & 1 & - & 2 & - & 1 \\
\hline 06 & $\begin{array}{c}\text { All Out } \\
\text { Poisoning }\end{array}$ & - & 2 & - & 1 & 1 & 1 & 2 & 2 \\
\hline 07 & $\begin{array}{l}\text { Alprazolam } \\
\text { Poisoning }\end{array}$ & - & 1 & - & - & 1 & - & 2 & 1 \\
\hline 08 & $\begin{array}{l}\text { Phenytoin } \\
\text { Toxicity }\end{array}$ & - & - & 1 & 1 & - & 1 & - & 1 \\
\hline 09 & $\begin{array}{l}\text { Camphor } \\
\text { Poisoning }\end{array}$ & - & - & 1 & 1 & - & 1 & - & 1 \\
\hline 10 & $\begin{array}{c}\text { Iron Folic } \\
\text { Acid Tablets } \\
\text { Poisoning }\end{array}$ & - & - & 1 & - & 1 & - & 1 & 1 \\
\hline 11 & $\begin{array}{l}\text { Eptoin Tablet } \\
\text { Poisoning }\end{array}$ & - & - & 1 & - & 1 & - & 3 & 1 \\
\hline 12 & $\begin{array}{l}\text { Unknown } \\
\text { Poisoning }\end{array}$ & - & - & 1 & - & 1 & - & 2 & 1 \\
\hline & Total & - & 19 & 10 & 11 & 18 & 16.8 & 17.1 & 29 \\
\hline
\end{tabular}

Table. 5. Poisoning due to Food

\begin{tabular}{|c|c|c|c|c|c|c|c|c|c|}
\hline \multirow[t]{2}{*}{ S. No. } & \multirow[t]{2}{*}{$\begin{array}{l}\text { Nature of } \\
\text { poisoning }\end{array}$} & \multicolumn{3}{|c|}{$\begin{array}{c}\text { Age group } \\
\text { (yrs) }\end{array}$} & \multicolumn{2}{|c|}{ Sex } & \multicolumn{2}{|c|}{$\begin{array}{c}\text { Duration of stay } \\
\text { (Avg .in days) }\end{array}$} & \multirow[t]{2}{*}{$\begin{array}{l}\text { Total } \\
\text { Cases }\end{array}$} \\
\hline & & Infants & Children & Adolescents & Male & Female & Male & Female & \\
\hline 1. & $\begin{array}{c}\text { Food } \\
\text { Poisoning }\end{array}$ & - & 5 & - & 1 & 4 & 60 & 37.5 & 5 \\
\hline
\end{tabular}

Perception of pediatricians towards the poison management guidelines framed during the study period was assessed and the results were reported in Table. 6.

Table. 6. Perception of pediatricians on the poison management guidelines

\begin{tabular}{|c|l|c|c|}
\hline S.No. & \multicolumn{1}{|c|}{ Questions about poison management guideline } & Yes & No \\
\hline 01 & Is it applicable under your hospital policies? & 12 & 00 \\
\hline 02 & Is it prepared according to best current clinical practices? & 12 & 00 \\
\hline 03 & Does your hospital have any related guidelines? & 12 & 00 \\
\hline 04 & Is your practice complimentary to this guidelines? & 12 & 00 \\
\hline 05 & Will your hospital accept this guidelines? & 12 & 00 \\
\hline
\end{tabular}

Out of 12 pediatricians 1 pediatrician has excellent satisfaction, 4 pediatricians have very good satisfaction, and 7 pediatricians have good satisfaction about quality of poison management guidelines. 


\section{Conclusion}

In conclusion, the rural district hospital which caters the healthcare needs of majority of the population in a wide geographical area, the number of reported cases of poisoning was fairly low for a period of 18 months. Higher awareness is required to prevent poisoning and to seek medical care. The order of the cases reported to the hospital was animal/insect bite, pesticide poisoning, and household poisoning. Incidences of animal/insect bite and pesticide poisoning were significantly higher in male children. Poisoning incidences were high in the age group of 1-11 years compared to younger or elder children. Duration of hospital stay was high for female children than males. Perception of paediatrician towards the poison management guidelines was very welcoming. It was found to be applicable, relevant, satisfactory, and complimentary to their real practice. Most of them anticipated that the guidelines shall be accepted under hospital treatment protocols.

\section{Acknowledgements}

The author would like to thank all faculties of Raghavendra Institute of Pharmaceutical Education and Research (RIPER) and Dr. Mohanraj Rathinavelu, Assistant Professor, Department of Pharmacy Practice, RIPER and Dr. Ketty Arce Cedilio, Family Medicine Doctor, In-charge, Casuality \& Critical Care, Rural Development Trust Hospital, Anantapuramu, Andhra Pradesh, India for their valuable guidance and constant support.

\section{References}

[1]. Chandha I A. Poisoning .Indian Journal of Anaesthesia, October 2003; 47 (5): 402-411.

[2]. World Health Statistics Annual. Geneva: World Health Organization, 1988.

[3]. Ernest Hodgson, Textbook of Modern Toxicology, $3^{\text {rd }}$ Ed. A John Wiley \& Sons, Inc., Publication, $2004,3$.

[4]. Doull J, Klaassen C, Amdur M. (Eds) In: Casarett and Doull's Toxicology. The Basic Science of Poisons. 3rd ed. Macmillan 1990.

[5]. Christopher H Linden, Michael J Burns. Poisoning and Drug Over dosage. In: Harrison's Principles of Internal Medicine. 15th ed. Braunwald, Fauci, Kasper, Hauser, Longe, Jameson. (Eds) McGraw Hill Publication. Ch 396, 2595-2629.

[6]. Dorland's "poison" at Dorland's Medical Dictionary $28^{\text {th }}$ ed.665.

[7]. Mofenson HC, Greensher J (1970). The nontoxic ingestion. Pediatric Clinics of North America.17 (3): 583 - 90.

[8]. Goldfrank, Flomenbaum, Lewin, Weisman, Howland, Hoffman (1998). Goldfrank's Toxicologic Emergencies (6 ${ }^{\text {th }}$ ed.). Stamford, Connecticut: Appleton \& Lange.

[9]. Stead, LG; Stead, SM; Kaufman, MS (2006). First Aid for the Emergency Medicine Clerkship (2nd ed.). McGraw-Hill. pp. 395-6.

[10]. Pillay VV. General Principles of poisons, in Modern Medical Toxicology, $3^{\text {rd }}$ ed. Jay Pee. pp. $1-3$ 